\title{
Comparison of the effect of calcium gluconate and batroxobin on the release of transforming growth factor beta 1 in canine platelet concentrates
}

\author{
Raul F Silva ${ }^{1,2^{*}}$, Jorge U Carmona ${ }^{2}$ and Cleuza MF Rezende ${ }^{1}$
}

\begin{abstract}
Background: The clinical use of autologous platelet concentrates (also known as platelet-rich plasma) on the field of regenerative therapy, in the last decade has been the subject of several studies especially in equine medicine and surgery. The objectives of this study was: 1) to describe and compare the cellular population in whole blood, lower fraction (A) and upper fraction (B) of platelet concentrates, 2) to measure and compare the transforming growth factor beta 1 (TGF- $\beta_{1}$ ) concentration in plasma and both platelet concentrates after be activated with calcium gluconate or batroxobin plus calcium gluconate and, 3) to determine correlations between cell counts in platelet concentrates and concentrations of TGF- $\beta_{1}$. Blood samples were taken from 16 dogs for complete blood count, plasma collection and platelet concentrates preparation. The platelet concentrates (PC) were arbitrarily divided into two fractions, specifically, PC-A (lower fraction) and PC-B (upper fraction). The Platelet concentrates were analyzed by hemogram. After activated with calcium gluconate or batroxobin plus calcium gluconate, TGF- $\beta_{1}$ concentration was determined in supernatants of platelet concentrates and plasma.

Results: There were differences statistically significant $(P<0.05)$ for the platelet count and leukocyte count and TGF- $\beta_{1}$ concentration between whole blood, plasma and both platelet concentrates. A significant correlation was found between the number of platelets in both platelet concentrates and TGF- $\beta_{1}$ concentration. Platelet collection efficiency was $46.34 \%$ and $28.16 \%$ for PC-A and PC-B, respectively. TGF- $\beta_{1}$ concentration efficiency for PC activated with calcium gluconate was $47.75 \%$ and $31.77 \%$, for PC-A and PC-B, respectively. PC activated with batroxobin plus CG showed $46.87 \%$ and $32.24 \%$ for PC-A and PC-B, respectively.
\end{abstract}

Conclusions: The methodology used in this study allows the concentration of a number of platelets and TGF- $\beta_{1}$ that might be acceptable for a biological effect for clinical or experimental use as a regenerative therapy in dogs.

Keywords: Tube method, Platelet Rich-Plasma, Dog, Regenerative medicine

\section{Background}

The healing process is directed by complex biological mechanisms that involve many cells and proteins, such as cytokines and growth factors (GF), among others. Cellular and molecular interactions allow, under physiological conditions, the repair or regeneration of damaged tissues [1,2]. Platelets play a central role in the healing

\footnotetext{
* Correspondence: raul.silva@ucaldas.edu.co

'Departamento de Clínica e Cirurgia Animal, Universidade Federal de Minas Gerais, Belo Horizonte, Brazil

${ }^{2}$ Grupo de Investigación Terapia Regenerativa, Departamento de Salud Animal, Universidad de Caldas, Manizales, Colombia
}

process. These cytoplasmic fragments not only have hemostatic properties [3], but also have pro-inflammatory, regulatory [4] and regenerative properties, which are mediated by interaction with other cells (neutrophils and endothelial cells), GF, chemokines and other regulatory molecules [5].

Currently, there is a growing interest in the use of autologous platelet concentrates (PC), also known as platelet rich plasma (PRP) for stimulating the healing process and promoting regeneration instead of reparation. Platelet alpha granules $[4,6]$ contain at least seven GF directly

\section{Biomed Central}


involved in the healing process. Of these proteins, transforming growth factor beta isoform 1 (TGF- $\left.\beta_{1}\right)$ is of pivotal importance for its actions on cell proliferation, angiogenesis and extracellular matrix deposition [7].

Many substances could potentially be used for platelet activation as a previous step for the clinical use PC. Platelet activation understood as a combination of fibrinogen cleavage leading to fibrin mesh formation and externalization of alpha granules containing growth factors [8]. Arbitrarily, activating substances could are classified according to their chemical structure in proteic, non-proteic forms and combination of both. Proteic activating substances include thrombin (either from bovine or autogenous sources) $[9,10]$, and soluble collagen type I [11] amongst others. Calcium salts, such as calcium chloride and calcium gluconate [9] are classified as nonproteic activating substances. Combination of both includes batroxobin plus calcium gluconate [10].

Some protocols for platelet activation include the use of a calcium salt solely and others include the combination of a calcium salt plus a proteic activating substance. To date, there is no convincing data about what is the best activating substance (in terms of GF concentration) for $\mathrm{PC}$ activation and more research is necessary to know the effect of these substances (either alone or combined) on the release of platelet main derived GF, such as TGF- $\beta_{1}$.

There is information on basic biological aspects and clinical use of PC in musculoskeletal and soft tissue injuries in human beings [12-15] and horses [16-18]. The study presented here provides the description of a manual protocol for producing two kinds of canine $\mathrm{PC}$ arbitrarily classified as lower fraction (PC-A) and upper fraction (PC-B) and evaluates the effect of a non-proteic activating substance (calcium gluconate -CG-) and the combination of a proteic activating substance (batroxobin) plus CG on the release of TGF- $\beta_{1}$ from canine PC.

The aims of this study were: 1 ) to describe and compare the cellular population in whole blood, lower fraction (A) and upper fraction (B) of platelet concentrates $(\mathrm{PC}), 2)$ to measure and compare the of TGF- $\beta_{1}$ concentration plasma in both $\mathrm{PC}$ after be activated with calcium gluconate (CG) or batroxobin plus CG and, 3) to determine correlations between cell counts in $\mathrm{PC}$ and concentrations of TGF- $\beta_{1}$.

\section{Results \\ Cells}

Platelet, WBC, and GRA counts were significantly different $(\mathrm{P}<0.01)$ between whole blood and both PC. PC-A showed the highest PLT and WBC counts. GRA concentration was highest in whole blood. The absolute count of LYM was significantly lower $(\mathrm{P}<0.01)$ in whole blood and $\mathrm{PC}-\mathrm{B}$ in comparison with $\mathrm{PC}-\mathrm{A}$. However, the relative count of LYM was significantly lower $(P<0.01)$ in whole blood in comparison with both PC. Absolute and relative counts of MID were similar for each blood component. MPV was significantly higher $(\mathrm{P}<0.01)$ in PC-A, in comparison with whole blood and PC-B. PDW was significantly different between each blood component (Table 1).

\section{Total protein concentration}

Total protein $(\mathrm{mg} / \mathrm{mL})$ concentration was similar for each blood component (Table 2).

\section{Transforming growth factor beta 1 concentration}

Independently of the activating substance used, the TGF- $\beta_{1}$ concentrations $(\mathrm{ng} / \mathrm{mL}$ or $\mathrm{ng} / \mathrm{mg}$ total protein) were significantly different $(\mathrm{P}<0.01)$ between plasma

Table 1 General results of the cellular variables. Data presented as mean (standard error)

\begin{tabular}{lcrr}
\hline \multirow{2}{*}{ Variable } & \multicolumn{3}{c}{ Blood component } \\
\cline { 2 - 4 } & Whole Blood & Platelet Concentrate-A & Platelet Concentrate-B \\
\hline $\mathrm{PLT} \times 10^{3} / \mu \mathrm{L}$ & $330.75(18.28) \mathrm{a}$ & $1072.90(84.01) \mathrm{b}$ & $652.00(56.47) \mathrm{c}$ \\
$\mathrm{PCV} \%$ & $45.50(1.05) \mathrm{a}$ & $5.81(1.01) \mathrm{a}$ & $1.58(0.84) \mathrm{c}$ \\
$\mathrm{WBC} \times 10^{3} / \mu \mathrm{L}$ & $10.94(0.77) \mathrm{a}$ & $17.86(2.56) \mathrm{b}$ & $4.46(1.27) \mathrm{c}$ \\
$\mathrm{LYM} \times 10^{3} / \mu \mathrm{L}$ & $2.27(0.25) \mathrm{a}$ & $11.38(1.63) \mathrm{b}$ & $3.44(1.26) \mathrm{a}$ \\
$\mathrm{LYM} \%$ & $20.97(2.08) \mathrm{a}$ & $65.78(3.41) \mathrm{b}$ & $67.18(6.82) \mathrm{b}$ \\
MID $\times 10^{3} / \mu \mathrm{L}$ & $0.49(007) \mathrm{a}$ & $0.61(0.21) \mathrm{a}$ & $0.23(0.10) \mathrm{a}$ \\
MID \% & $4.49(0.55) \mathrm{a}$ & $3.08(0.79) \mathrm{a}$ & $3.60(0.93) \mathrm{a}$ \\
GRA $\times 10^{3} / \mu \mathrm{L}$ & $8.20(0.68) \mathrm{a}$ & $5.85(1.11) \mathrm{b}$ & $0.77(0.22) \mathrm{c}$ \\
GRA \% & $74.54(2.01) \mathrm{a}$ & $31.14(3.60) \mathrm{b}$ & $29.22(2.38) \mathrm{c}$ \\
MPV (fL) & $8.36(0.18) \mathrm{a}$ & $8.80(0.17) \mathrm{b}$ & $8.31(0.13) \mathrm{a}$ \\
PDW \% & $35.53(0.47) \mathrm{a}$ & $36.79(0.37) \mathrm{b}$ & $35.45(0.45) \mathrm{a}$ \\
\hline
\end{tabular}

Statistically significant differences by SNK test. ${ }^{a, b, c}$ Different letters represent significant $(P<0.01)$. 
Table 2 Concentration of transforming growth factor beta 1 in plasma and supernatants of platelet concentrates (PC). Data presented as mean (standard error)

\begin{tabular}{|c|c|c|c|c|}
\hline \multirow{2}{*}{ Activating substance } & \multirow{2}{*}{ Variable } & \multicolumn{3}{|c|}{ Blood component } \\
\hline & & Plasma & PC-A & PC-B \\
\hline \multirow[t]{3}{*}{ Calcium Gluconate } & $\mathrm{TGF}-\beta_{1}(\mathrm{ng} / \mathrm{mL})$ & $13.7(2.88)$ a & $45.8(5.43) b$ & $30.5(3.11) c$ \\
\hline & $\mathrm{TP}(\mathrm{mg} / \mathrm{mL})$ & $62.0(0.96)$ a & $62.3(0.79)$ a & $62.6(1.06) \mathrm{a}$ \\
\hline & TGF- $\beta_{1}$ (ng/mg of TP) & $0.22(0.05)$ a & $0.73(0.09) b$ & $0.49(0.05) c$ \\
\hline \multirow[t]{3}{*}{ Batroxobin plus calcium gluconate } & $\mathrm{TGF}-\beta_{1}(\mathrm{ng} / \mathrm{mL})$ & $13.7(2.88) \mathrm{a}$ & $44.9(5.65) b$ & $30.9(3.20) c$ \\
\hline & $\mathrm{TP}(\mathrm{mg} / \mathrm{mL})$ & $62.0(0.96)$ a & $63.1(1.25) \mathrm{a}$ & $64.7(1.65) \mathrm{a}$ \\
\hline & TGF- $\beta_{1}(n g / m g$ of TP) & $0.22(0.05) \mathrm{a}$ & $0.72(0.09) \mathrm{b}$ & $0.48(0.05) c$ \\
\hline
\end{tabular}

Statistically significant differences by SNK test. ${ }^{a, b, c}$ Different letters represent significant $(P<0.01)$.

and both PC. The highest TGF- $\beta_{1}$ concentration was found in $\mathrm{PC}$-A. No differences were noted between the two activating substances on the release of TGF- $\beta_{1}$ of both PC (Table 2).

\section{Correlations}

Highly significant correlations were found for PLT count and TGF- $\beta_{1}$ concentration in both PC, independently of the activating substance used. For platelet concentrates activated with CG the correlation coefficients were $\rho=0.7$ $(\mathrm{P}<0.01)$ and $\rho=0.75(\mathrm{P}<0.01)$ for $\mathrm{PC}-\mathrm{A}$ and $\mathrm{PC}-\mathrm{B}$, respectively. For platelet concentrates activated with batroxobin plus CG the correlation coefficients were $\rho=0.71$ $(\mathrm{P}<0.01)$ and $\rho=0.75(\mathrm{P}<0.01)$ for $\mathrm{PC}-\mathrm{A}$ and $\mathrm{PC}-\mathrm{B}$, respectively.

\section{Collection (concentration) efficiency}

Platelet collection efficiency was $46.34 \%$ and $28.16 \%$ for PC-A and PC-B, respectively. The combined collection efficiency for both PC was $74.5 \%$. Platelet concentration was $224.38 \%$ for PC-A and $97.13 \%$ for PC-B in comparison with platelet counts in whole blood. Data of TGF- $\beta_{1}$ concentration efficiency for each PC after activation with CG and batroxobin plus CG is presented in Table 3.

\section{Discussion}

This research describes a reliable method for producing platelet concentrates and consequently for concentrating GF, such as TGF- $\beta_{1}$ from canine blood. Some manual (tube) protocols [19-22] and a semi-automated method [23] have been described for producing PC in dogs.

Table 3 Concentration efficiency of transforming growth factor beta 1 in supernatants of platelet concentrates (PC)

\begin{tabular}{llccc}
\hline \multirow{2}{*}{ Activating substance } & \multirow{2}{*}{ Variable } & \multicolumn{3}{c}{ Blood component } \\
\cline { 3 - 5 } & & PC-A & PC -B & PC-A + B \\
\hline Calcium gluconate & TGF- $\beta_{1}(\%)$ & 47.8 & 31.8 & 165.57 \\
Batroxobin plus calcium gluconate & TGF- $\beta_{1}(\%)$ & 46.9 & 32.2 & 158.22 \\
\hline
\end{tabular}

Manual protocols were performed with either sodium citrate [19-21] or ACD-A [22] as anticoagulant. Those protocols included simple and double centrifugation steps for concentrating between $400 \times 10^{3}$ to $1300 \mathrm{X}$ $10^{3} \mathrm{PLT} / \mu \mathrm{L}$. However, platelets were counted manually (light microscopy) and did not report additional hematologic features of the resulting PC.

Platelet concentration reached in the protocol described here was slightly lower than a semi-automated double centrifugation method evaluated in dogs, which presented a median concentration of $1336 \mathrm{PLT} X 10^{3} / \mu \mathrm{L}$ [23]. However, this method is limited because it could only be used in medium at large breed dogs, since it requires $60 \mathrm{~mL}$ of blood for $\mathrm{PC}$ preparation. The protocol described here presents the advantage that $\mathrm{PC}$ is easily obtained by using one centrifugation step with a small volume of blood. This last situation is important when pediatric patients or small breed dogs are treated.

The size and weight of the blood cells, the relative centrifugation forces (g) and time are factors that determine the cellular and molecular characteristics of a PC. This concept is necessary for comparing the results of the research described here with other published studies in human beings [12-15] and horses [16-18]. The protocol described here permitted obtaining two kinds of different PC. Platelet concentrate-A presented a higher concentration of $\mathrm{PLT} / \mu \mathrm{L}, \mathrm{WBC} / \mu \mathrm{L}$ and TGF- $\beta_{1} / \mathrm{mL}$ (independently of the activating substance used) in comparison with PC-B. From a comparative point of view both canine and human blood present the same trend when centrifuged for PC preparation. However, equine blood requires a double centrifugation [24] for obtaining a PC with an acceptable quantity of PLT.

There are a lot of controversies about the ideal number of concentrated platelets in a PC for its clinical use in human beings and horses. Some researches consider the highest number of platelets concentrated in PRP to yield the best clinical results. This assumption could emerge from experimental results observed in rabbits where higher platelet concentrations were better for osteointegration, than lower platelet concentration [25]. 
However, excellent clinical results have been observed in human beings [26] and horses [16] using PC with $300-400 \times 10^{3} \mathrm{PLT} / \mu \mathrm{L}$.

Another fact that generates controversy is the presence of leukocytes in PC. Some researches consider that WBC are a contaminant of PRP and possibly deleterious for tissues when treated, especially at high concentrations. However, others believe that WBC are important regulatory cells contained in PRP and necessary for wound healing [27]. To date, there are no studies that definitively elucidate the significance of leukocytes in PRP. However, when manual methods are used for producing $\mathrm{PC}$ in human beings and horses, leukocyte concentrations are comparatively lower when semi-automated methods are used. Unfortunately, there is no data about WBC concentration in canine PC obtained by manual or semi-automated methods. However, it is important to note that platelet concentration of the protocol described here was not correlated with WBC concentration. This situation is different for PC derived from equine blood [24].

Both PC obtained in this study permitted concentrate two (PC-B) and three (PC-A) fold the concentration of TGF- $\beta_{1}$ respect to the basal concentration of this protein in plasma. These findings suggest that plasma platelets were scarcely activated at the moment of blood extraction, since the MPV remained lower in whole blood in comparison with the same parameter in PC-A. However, although MPV value was statistically higher in PC-A in comparison with $\mathrm{PC}-\mathrm{B}$ and whole blood, this platelet activation parameter remained between normal range values for canine platelets [28]. Maybe, the reason, which MPV was higher in PC-A, is related to the large number of concentrated PLT and WBC. A single centrifugation process produces cellular friction that could be most active toward the platelet fraction near to the erythrocyte package. This situation has also been observed in equine PC obtained by simple and double centrifugation tube methods [24].

Plasma TGF- $\beta_{1}$ concentrations of this study were quite similar to the values described for this protein from serum of two dogs (16.5 and $19.9 \mathrm{ng} / \mathrm{mL}$ ) [29]. However, other research described plasma TGF- $\beta_{1}$ concentration ranging from $0.193-0.598 \mathrm{ng} / \mathrm{mL}$. That study included 29 canine blood samples collected with EDTA by using a double centrifugation protocol [30]. Plasma or serum TGF- $\beta_{1}$ concentrations described in these two last studies $[29,30]$ could be influenced by methodological aspects such as the use or not of anticoagulant and the type of antibody used for TGF- $\beta_{1}$ measurement. To note, this protein was measured in the present study with a specific canine antibody for TGF- $\beta_{1}$, whereas the studies mentioned $[29,30]$ used a human TGF- $\beta_{1}$ antibody. However, this is only an assumption and further studies are necessary to validate the actual utility of human or canine ELISA kits for canine TGF- $\beta_{1}$ measurement.

Plasma and both $\mathrm{PC}$ of this study presented higher concentrations of TGF- $\beta_{1}$ in comparison with the results of the same protein from autologous conditioned plasma (ACP) and plasma obtained with ACD-A from blood of dogs [31]. In that research [31], a TGF- $\beta_{1}$ mean concentration of $1.24 \pm 0.59 \mathrm{ng} / \mathrm{mL}$ was obtained from ACP with PLT counts ranging from $277-293.5 \times 10^{3} / \mu \mathrm{L}$. However, the ELISA human kit used did not detect plasma TGF- $\beta_{1}$ concentration. In addition, no statistical correlation was found between the number of PLT concentrated and the TGF- $\beta_{1}$ concentrations [31]. This last result was different from the findings of the study described here; since strong correlations $(70 \%)$ were noticed between PLT counts and TGF- $\beta_{1}$ concentration. The difference between the results obtained in that study [31] and the findings of the research presented here could be related to the specificity of the antibody used for TGF- $\beta_{1}$ detection and because they used no activating substances for stimulating the release of growth factors from platelets.

There is some controversy about the need of adding activating substances to induce the release of GF contained in PLT. Some researchers think that activating substances are not necessary when PC will be used as an injection for the treatment of tendon and ligament lesions or arthropaties [32]. They argue that connective tissues are rich in collagen and that this autologous protein is enough to induce platelet activation. Other researchers believe that the use of activating substances is necessary to stimulate the massive release of growth factors in the foci of the lesion and thus increasing the healing process of the affected tissue [32]. However, to date there is no scientific information to determine if activating substances should be used before PC injection.

Platelet activating substances are a necessary prerequisite for producing platelet gel from PC. Platelet gels are used for covering large skin defects or for filling bone defects either alone or combined with other biomaterials. Platelet gels could be produced from PC activated with proteic and non-proteic substances or by combination of both. Classically, bovine thrombin (either alone or in combination with a calcium salt) has been used for platelet gel production. Thrombin induces fibrin polymerization by removing fibrinopeptides $\mathrm{A}$ and $\mathrm{B}$ from the fibrin molecule. This protein also produces platelet activation and massive release of growth factors. Some clinicians prefer not to use bovine thrombin for platelet gel formation because this substance induces crossreacting antibodies against coagulation factors V and XI [9].

Batroxobin induces fibrin polymerization by removing only the fibrinopeptide A. This substance does not induce platelet activation or immunological reactions 
against coagulation factors [9]. The manufacturer recommends the use of batroxobin plus calcium gluconate for platelet gel formation. In the study presented here no differences were noticed on the release of TGF- $\beta_{1}$ from both PC activated with CG or batroxobin plus CG. Macroscopically no differences were noted about the quality of the platelet gel formed or the time required for clot formation. However, one limitation of this study is that kinetics of gelation was not performed [9].

Results of this study corroborate that batroxobin induce negligible platelet activation and the addition of CG was necessary to induce the TGF- $\beta_{1}$ release. This phenomenon could be explained without the need of using an experimental group of PC activated only with batroxobin, since TGF- $\beta_{1}$ concentration was statistically similar for both $\mathrm{PC}$, independently of the activating substance used, CG or batroxobin plus CG. This study is limited since TGF- $\beta_{1}$ release only was measured at once. Further studies are necessary for knowing if the release kinetics of this growth factor is time dependent or is related to an activating substance in particular.

Collection and concentration efficiencies are two important aspects related with the capacity of and protocol or device for concentrating the most possible number of platelets and growth factors from a whole blood sample. The protocol described here for producing PC and consequently concentrating TGF- $\beta_{1}$ was better than the cellular and molecular results obtained for canine ACP protocol [31] and the platelet concentration efficiency described for a semi-automated method for producing canine PRP [23].

\section{Conclusions}

In summary, this study describes a simple and inexpensive manual tube protocol for producing two PC with different cellular and molecular characteristics. Release of TGF- $\beta_{1}$ from both $\mathrm{PC}$ at $2 \mathrm{~h}$ post-activation was mainly dependent of CG. Further research is necessary to determine the quality and strength of the platelet gel formed before PC activation with CG or batroxobin (either alone or in combination with CG). A study on the kinetics of release of TGF- $\beta_{1}$ and other platelet storage growth factors from PC activated with several substances during several hours should be performed.

Clinical studies are necessary to determine the actual clinical utility of each PC produced with the protocol of this study. Aspects related with the cellular or molecular composition of PC possibly will determine the specific use of each biodrug for a particular disease or tissue. The use of platelet activating substance also will determine the specific clinical use of PC in dogs.

\section{Methods}

The ethics committee of animal research of Federal University of Minas Gerais approved this study.

\section{Animals}

Sixteen male mongrel dogs were used, with age range between 16 to 24 months and $15 \mathrm{Kg}$ of average weight, clinically healthy at time of blood collection and serologically negative for leishmaniasis and ehrlichiosis.

\section{Preparation of platelet concentrates}

Blood collection was performed by puncturing the saphenous vein with a butterfly catheter $21 \mathrm{G}$ (Shandong Weigao Group, Weihai, China). Blood was placed in $8.5 \mathrm{~mL}$ tubes with $1.5 \mathrm{~mL}$ of ACD-A (trisodium citrate $22 \mathrm{~g} / \mathrm{L}$, citric acid $8 \mathrm{~g} / \mathrm{L}$ and dextrose $24.5 \mathrm{~g} / \mathrm{L}$ ) (Becton Dickinson and Company, New Jersey, USA). Tubes were centrifuged (SIGMA 3 K30, Osterode am Harz, Germany) at $191 \mathrm{~g}$ for 6 minutes. Arbitrarily, the plasma derived from blood centrifugation was divided in two equal fractions, PC-A and PC-B. PC-A (lower PC fraction) was considered as the first $50 \%$ of plasma next to the packed cell volume (PCV) and PC-B (upper PC fraction) was the $50 \%$ of remaining plasma in the tube.

\section{Cellular evaluation}

Blood samples and both PC were analyzed for hemogram by using an automated counting device by volumetric impedance (Abacus Junior Vet, Budapest, Hungary). Each sample was analyzed by triplicate. The hematological parameters tested were hematocrit $(\mathrm{PCV})$, platelet count $(\mathrm{PLT} / \mu \mathrm{L})$, leukocyte count $(\mathrm{WBC} / \mu \mathrm{L})$, absolute counts (cells $/ \mu \mathrm{L}$ ) and relative values (\% cells) of lymphocytes (LYM), monocytes (MID), neutrophils, eosinophils and basophils (GRA), mean platelet volume (MPV fL) and platelet distribution width (PDW \%).

\section{Activation of platelet concentrates}

Samples of one $\mathrm{mL}$ from PC-A and PC-B were divided into aliquots of $500 \mu \mathrm{L}$ and then activated with $50 \mu \mathrm{L}$ of CG 10\% (Ropsohn Therapeutics Ltda, Bogotá, Colombia) or batroxobin (Plateltex, Praha, Czech Republic) reconstituted with one $\mathrm{mL}$ of CG 10\% (Ropsohn Therapeutics Ltda, Bogotá, Colombia). After activated, the samples were kept in incubation at room temperature $\left(22^{\circ} \mathrm{C}\right)$ for two hours [24]. Fibrin clots in each PC sample were released from the tube walls and centrifuged at $1500 \mathrm{~g}$ for 10 minutes. Further, others plasma samples were obtained by the centrifugation protocol described above. The supernatants of activated PC and plasma samples were aliquoted and frozen at $-80^{\circ} \mathrm{C}$ for later determination of TGF- $\beta_{1}$ concentration.

\section{Determination of total protein}

Total protein (TP) concentration was measured by duplicate in both PC and plasma by using the biuret method (Biosystems, Barcelona, Spain) in a semiautomatic chemistry analyser (RT-1904CV, Nanjing, China). 
This determination was performed to know the proportion of TGF- $\beta_{1} /$ TP released during PC activation.

\section{Determination of the concentration of transforming growth factor beta 1}

Concentration of TGF- $\beta_{1}(\mathrm{ng} / \mathrm{mL})$ in plasma and both PC were determined by ELISA sandwich, specifically developed with antibodies against canine TGF- $\beta_{1}$ (Mouse/ Rat/Porcine/Canine TGF- $\beta_{1}$, MB100B, R\&D Systems, Minneapolis, USA). This protein had a mean detection sensitivity of $4.6 \mathrm{pg} / \mathrm{mL}$. ELISA was performed by duplicate for each sample according to the manufacturer instructions. Reading (Biochrom, Anthos 2010, Cambridge, UK) was performed at $450 \mathrm{~nm}$.

\section{Statistically analysis}

Data derived from this study presented normal distribution (Shapiro-Wilk test, $\mathrm{P}>0.05$ ) and analyzed variables were presented as mean and mean standard error. Comparison between groups was performed using a one-way ANOVA and post-hoc par-wise comparisons were performed with a Student-Newman-Keuls (SNK) test. Correlations between TGF- $\beta_{1}$ concentrations and cellular data were performed using a Pearson $(\rho)$ test. A value of $\mathrm{P} \leq 0.01$ was accepted as statistical significant for all the tests.

\section{Collection (concentration) efficiency}

Platelet collection efficiency was determined by the formula: ( $\mathrm{PC}$ volume $\mathrm{x}$ platelet count in the $\mathrm{PC} /$ whole blood volume $\mathrm{x}$ platelet count in whole blood) $\mathrm{x} 100$ [33].

TGF- $\beta_{1}$ concentration efficiency was determined by the formula:(concentration of TGF- $\beta_{1}$ in PC $(\mathrm{ng} / \mathrm{mL}) \mathrm{x}$ volume of PC/plasmaTGF- $\beta_{1}$ concentration $(\mathrm{ng} / \mathrm{mL}) \mathrm{x}$ whole blood volume) x 100 [34].

\section{Authors' contributions}

RFS conceived of the study, performed the laboratory tests, performed the statistical analysis and participated in the drafting of the manuscript. CMFR participated in the design and participated in the drafting of the manuscript. JUC coordinated the study, participated in the design and harmonized the drafting of the manuscript. All authors read and approved the final manuscript.

\section{Acknowledgements}

The authors thank Dr. Piero Borzini for his technical criticisms to this manuscript and Andrea Vecchiato from Plateltex. We thank Coordenação de Aperfeiçoamento de Pessoal de Nível Superior - CAPES and Fundação do Amparo à Pesquisa do Estado de Minas Gerais - FAPEMIG, Brazil.

Received: 3 May 2012 Accepted: 4 July 2012

Published: 25 July 2012

\section{References}

1. Enoch S, Leaper DJ: Basic science of wound healing. Surgery 2008, 26(2):31-37.

2. Beldon P: Basic Science of wound healing. Surgery 2010, 28(9):409-412.

3. Hartwig J, Italiano J: The birth of the platelet. J Thromb Haemost 2003, 1(7):1580-1586
4. Mannaioni PF, Di Bello GM, Masini E: Platelets and inflammation: role of platelet-derived growth factor, adhesion molecules and histamine. Inflamm Res 1997, 46(1):4-18.

5. Anitua E, Andía I, Ardanza B, Nurden P, Nurden A: Autologous platelets as a source of proteins for healing and tissue regeneration. Thromb Haemost 2004, 91(1):4-15.

6. Pelagalli A, Lombarda D, D'Angelo R, Della Morte R, Avallone L, Staiano N: Species variability in platelet aggregation response to different agonists. J Comp Pathol 2002, 127(2-3):126-132.

7. Lee KS, Wilson JJ, Rabago DP, Baer GS, Jacobson JA, Borrero CG: Musculoskeletal Applications of Platelet-Rich Plasma: Fad or Future? AJR Am J Roentgenol 2011, 196(3):628-636.

8. Dohan DM, Choukroun J, Diss A, Dohan SL, Dohan AJ, Mouhyi J, Gogly B: Platelet-rich fibrin (PRF): a second-generation platelet concentrate. Part II: platelet-related biologic features. Oral Surg Oral Med Oral Pathol Oral Radiol Endod 2006, 101(3):e45-e50.

9. Mazzucco L, Balbo V, Cattana E, Borzini P: Platelet-rich plasma and platelet gel preparation using Plateltex. Vox Sang 2008, 94(3):202-208.

10. Mazzucco L, Balbo V, Cattana E, Guaschino R, Borzini P: Not every PRP-gel is born equal. Evaluation of growth factor availability for tissues through four PRP-gel preparations: Fibrinet, RegenPRP-Kit, Plateltex and one manual procedure. Vox Sang 2009, 97(2):110-118.

11. Jennings LK: Mechanisms of platelet activation: need for new strategies to protect against platelet-mediated atherothrombosis. Thromb Haemost 2009, 102(2):248-257.

12. Sánchez M, Azofra J, Anitua E, Andía I, Padilla S, Santisteban J, Mujika I: Plasma rich in growth factors to treat an articular cartilage avulsion: a case report. Med Sci Sports Exerc 2003, 35(10):1648-1652.

13. Alio $J \mathrm{~L}$, Abad M, Artola A, Rodriguez-Prats JL, Pastor S, Ruiz-Colecha J: Use of autologous platelet-rich plasma in the treatment of dormant corneal ulcers. Ophthalmology 2007, 114(7):1286-1293.

14. Thor A, Franke-Stenport V, Johansson CB, Rasmusson L: Early bone formation in humans bone grafts treated with platelet-rich plasma: preliminary histomorphometric results. Int J Oral Maxillofac Surg 2007, 36(12):1164-1171.

15. Greppi N, Mazzucco L, Galetti G, Bona F, Petrillo E, Smacchia C, Raspollini E, Cossovich P, Caprioli R, Borzini P, Rebulla P, Marconi M: Treatment of recalcitrant ulcers with allogeneic platelet gel from pooled platelets in aged hypomobile patients. Biologicals 2011, 39(2):73-80.

16. Carmona JU, Argüelles D, Climent F, Prades M: Autologous platelet concentrates as a treatment of horses with osteoarthritis: A preliminary pilot clinical study. J Equine Vet Sci 2007, 27(4):167-170.

17. Argüelles D, Carmona JU, Climent F, Muñoz E, Prades M: Autologous platelet concentrates as a treatment for musculoskeletal lesions in five horses. Vet Rec 2008, 162(7):208-211.

18. Waselau M, Sutter WW, Genovese RL, Bertone AL: Intralesional injection of platelet-rich plasma followed by controlled exercise for treatment of midbody suspensory ligament desmitis in Standardbred racehorses. J Am Vet Med Assoc 2008, 232(10):1515-1520.

19. Choi BH, Zhu SJ, Kim BY, Huh SH, Lee SH, Jung JH: Effect of platelet-rich plasma (PRP) concentration on the viability and proliferation of alveolar bone cells: an in vitro study. Int J Oral Maxillofac Surg 2005, 34(4):420-424.

20. Ferraz VCM, Ferrigno CRA, Schmaedecke A: Platelet concentration of platelet rich plasma from dog, obtained through three centrifugation speeds. Braz J Vet Res Anim Sci 2007, 44(6):435-440.

21. You TM, Choi BH, Li J, Jung JH, Lee HJ, Lee SH, Jeong SM: The effect of platelet-rich plasma on bone healing around implants placed in bone defects treated With Bio-oss: a pilot study in the dog tibia. Oral Surg Oral Med Oral Pathol Oral Radiol Endod 2007, 103(4):e8-e12.

22. Li NY, Yuan RT, Chen T, Chen LQ, Jin XM: Effect of Platelet-Rich Plasma and Latissimus Dorsi Muscle Flap on Osteogenesis and Vascularization of TissueEngineered Bone in Dogs. J Oral Maxillofac Surg 2009, 67(9):1850-1858.

23. Thoesen MS, Vander-Berg-Foels WS, Stokol T, Rassnick KM, Jacobson MS, Kevi SB, Todhunter RJ: Use of a centrifugation-based, point-of-care device for production of canine autologous bone marrow and platelet concentrates. Am J Vet Res 2006, 67(10):1655-1661.

24. Argüelles D, Carmona JU, Pastor J, Iborra A, Viñals L, Martínez P, Bach E, Prades M: Evaluation of single and double centrifugation tube methods for concentrating equine platelets. Res Vet Sci 2006, 81(2):237-245.

25. Weibrich G, Hansen T, Kleis W, Buch R, Hitzler WE: Effect of platelet concentration in platelet-rich plasma on peri-implant bone regeneration. Bone 2004, 34(4):665-671. 
26. Marx RE: Platelet-rich plasma: Evidence to support its usage. J Oral Maxillofac Surg 2004, 62(4):489-496.

27. Park JE, Barbul A: Understanding the role of immune regulation in wound healing. Am J Surg 2004, 187(5A):11-16.

28. Vagdatli E, Gounari E, Lazaridou E, Katsibourlia E, Tsikopoulou F, Labrianou I: Platelet distribution width: a simple, practical and specific marker of activation of coagulation. Hippokratia 2010, 14(1):28-32.

29. Vercelli A, Bellone G, Abate O, Emanuelli G, Cagnasso A: Expression of transforming growth factor-beta isoforms in the skin, kidney, pancreas and bladder in a German shepherd dog affected by renal cystadenocarcinoma and nodular dermatofibrosis. I Vet Med A Physiol Pathol Clin Med 2003, 50(10):506-510.

30. Neumann S, Kaup FJ, Beardi B: Plasma concentration of transforming growth factor-beta1 and hepatic fibrosis in dogs. Can J Vet Res 2008, 72(5):428-431.

31. Stief M, Gottschalk J, lonita JC, Einspanier A, Oechtering G, Böttcher P: Concentration of platelets and growth factors in canine autologous conditioned plasma. Vet Comp Orthop Traumatol 2011, 24(2):122-1225.

32. Mishra A, Woodall J, Vieira A: Treating of tendon and muscle using Platelet-rich plasma. Clin Sports Med 2009, 28(1):113-125.

33. Weibrich G, Kleis WK, Buch R, Hitzler WE, Hafner G: The Harvest Smart $\mathrm{PReP}^{\mathrm{TM}}$ system versus the Friadent-Schütze platelet-rich plasma kit. Clin Oral Implants Res 2003, 14(2):233-239.

34. Weibrich $G$, Kleis WK, Hitzler WE, Hafner G: Comparison of the platelet concentrate collection system with the plasma-rich-in growth factors kit to produce platelet rich plasma: a technical report. Int J Oral Maxillofac Implants 2005, 20(1):118-123.

doi:10.1186/1746-6148-8-121

Cite this article as: Silva et al:: Comparison of the effect of calcium gluconate and batroxobin on the release of transforming growth factor beta 1 in canine platelet concentrates. BMC Veterinary Research 2012 8:121.

\section{Submit your next manuscript to BioMed Central and take full advantage of:}

- Convenient online submission

- Thorough peer review

- No space constraints or color figure charges

- Immediate publication on acceptance

- Inclusion in PubMed, CAS, Scopus and Google Scholar

- Research which is freely available for redistribution 